\title{
Гиалуроновая кислота:
}

\section{перспективы использования в гинекологии}

\author{
А.В. Соколова, И.А. Аполихина \\ ФГБУ «Национальный медицинский исследовательский центр акушерства, гинекологии и перинатологии имени академика \\ В.И. Кулакова» Министерства здравоохранения Российской Федерации; Россия, г. Москва
}

\section{PEЗЮME}

\begin{abstract}
Цель обзора: рассмотреть перспективы использования в гинекологии гиалуроновой кислоты (ГК).
Основные положения. Проведен анализ публикаций, описывающих применение ГК в гинекологии. Представлен также собственный клинический опыт использования объемообразующих средств для интимной контурной пластики.

Заключение. Применение препаратов на основе натрия гиалуроната является хорошей альтернативой в лечении урогинекологических заболеваний, сопровождающихся сухостью, недержанием мочи и различными эстетическими нарушениями. Однако необходимо соблюдать показания и противопоказания, так как описаны случаи осложнений после интимной контурной пластики.

Ключевые слова: гиалуроновая кислота, интимная контурная пластика, объемообразующие средства, биоревитализация вульвы, эстетическая гинекология, осложнения.
\end{abstract}

Вклад авторов: Соколова А.В. - обзор публикаций по теме статьи, написание текста рукописи; Аполихина И.А. — редактирование, утверждение рукописи в печать.

Конфликт интересов: авторы заявляют об отсутствии возможных конфликтов интересов.

Для цитирования: Соколова А.В., Аполихина И.А. Гиалуроновая кислота: перспективы использования в гинекологии. Доктор.Ру. 2021; 20(8): 36-40. DOI: 10.31550/1727-2378-2021-20-8-36-40

\section{Hyaluronic Acid: Prospective Use in Gynaecology}

\author{
A.V. Sokolova, I.A. Apolikhina \\ V.I. Kulakov National Medical Scientific Centre of Obstetrics, Gynecology and Perinatal Medicine of the Ministry of Health of the Russian \\ Federation; 4 Academician Oparin Str., Moscow, Russian Federation 117997
}

\section{ABSTRACT}

Objective of the Review: To discuss prospective use of hyaluronic acid (HA) in gynaecology.

Key Points. We have reviewed publications describing the use of HA in gynaecology. Also, we are presenting our own clinical experience in the use of volumizing products for intimate contour correction.

Conclusion. The use of sodium hyaluronate preparations is a good alternative in the management of genitourinary diseases associated with dryness, incontinence and various aesthetic disturbances. However, the indications and counterindications need to be taken into account, since there are evidences of complications from intimate contour correction.

Keywords: hyaluronic acid, intimate contour correction, volumizing products, vulvar biorevitalization, aesthetic gynaecology, complications.

Contributions: Sokolova, A.V. - review of thematic publications, text of the article; Apolikhina, I.A. - editing, approval of the manuscript for publication.

Conflict of interest: The authors declare that they do not have any conflict of interests.

For citation: Sokolova A.V., Apolikhina I.A. Hyaluronic Acid: Prospective Use in Gynaecology. Doctor.Ru. 2021; 20(8): 36-40. (in Russian). D0I: 10.31550/1727-2378-2021-20-8-36-40

B ведение объемообразующих средств на основе гиалуроновой кислоты (ГК) в область гениталий относится к новым минимально инвазивным и наиболее востребованным амбулаторным процедурам. Синтетические наполнители на основе ГК применяются с 1990 годов во всем мире. Однако наиболее безопасные препараты стали использоваться с 2003 года, в том числе в гинекологии. Они хорошо зарекомендовали себя благодаря низкому риску развития аллергических реакций $(1: 2000)$ и стабильному результату, сохраняющемуся до 1-1,5 года [1].

ГК - полисахарид, в большей степени ответственный за характеристики соединительной ткани. Основная функция ГК - структурообразующая, она реализуется в дермальных слоях кожи. Благодаря высокой гидрофильности (способности захватывать и удерживать молекулы воды) ГК формирует прочную трехмерную структуру межклеточного

Соколова Анастасия Владимировна (автор для переписки) - к. м. н., врач акушер-гинеколог отделения эстетической гинекологии и реабилитации ФГБУ «НМИЦ АГП им. В.И. Кулакова» Минздрава России. 117997, Россия, г. Москва, ул. Академика Oпарина, д. 4. eLIBRARY.RU SPIN: 3875-6251.E-mail: stasia0590@mail.ru

Аполихина Инна Анатольевна - д. м. н., профессор, врач акушер-гинеколог высшей категории, физиотерапевт, руководитель отделения эстетической гинекологии и реабилитации ФГБУ «НМИЦ АГП им. В.И. Кулакова» Минздрава России. 117997, Россия, г. Москва, ул. Академика Onapuнa, D. 4. eLIBRARY.RU SPIN: 6282-7435. https://orcid.org/0000-0002-4581-6295. E-mail: apolikhina@inbox.ru 
матрикса, способного адаптироваться к изменениям условий внешней среды: давлению, удару, трению, тепловому воздействию. Кроме того, ГК участвует в заживлении ран, передаче сигналов, инактивации свободных радикалов при окислительном стрессе, овуляции, оплодотворении, морфогенезе плаценты и даже в физиологии опухолей $[2,3]$.

\section{ПРИМЕНЕНИЕ ГИАЛУРОНОВОЙ \\ КИСЛОТЫ В ГИНЕКОЛОГИИ}

Инъекционные методы введения препаратов на основе ГК (ПГК), применяющиеся в гинекологии, можно разделить на нижеследующие.

Интимная контурная пластика/интимный филлинг введение препаратов на основе стабилизированной ГК (филлеров) с целью изменения формы и объема влагалища и наружных половых органов и коррекции стрессового недержания мочи.

Биоревитализация - введение препаратов на основе нестабилизированной (нативной) ГК. Биоревитализация нормализует тканевой гомеостаз, способствует гидратации тканей и стимулирует неоколлагенез [4, 5]. Используется для лечения и профилактики атрофических изменений слизистых влагалища и кожи наружных половых органов, в то время как интимная контурная пластика предназначена для коррекции дефектов половых губ и входа во влагалище в случае дефицита жировой ткани, рубцовой деформации, синдрома релаксации влагалища и сексуальной дисфункции.

Для каждого метода используются препараты, отличающиеся составом, массой и концентрацией ГК. Так, например, несшитая ГК применяется в комплексном лечении атрофических изменений кожи и слизистых области гениталий. А наиболее плотные филлеры вводятся для коррекции недержания мочи и дистопии уретры, интимной контурной пластики.

В настоящее время ПГК признаны безопасными и эффективными средствами для восстановления кожи: они уменьшают выраженность рубцевания и способствуют регенерации и заживлению тканей за счет стимуляции пролиферации и дифференцировки фибробластов, что приводит к увеличению содержания коллагена, гликозаминогликанов и гиалуронана кожи [6-11].

В эксперименте на животных установлено, что интрадермальное введение ГК сначала сопровождается асептической воспалительной реакцией (отеком тканей, разрыхлением структуры внеклеточного матрикса, незначительной диффузной инфильтрацией макрофагами и, в меньшей степени, лимфоцитами), повышением содержания в сыворотке крови провоспалительных цитокинов - ИЛ-1 $\beta$, ФН0- $\alpha$, в более поздние сроки - пролиферацией клеточных элементов кожи и усилением биосинтетической активности фибробластов [12].

Методом иммуногистохимии после применения ПГК в коже определяется возрастание количества клеток, экспрессирующих белок Кі-67 и фактор роста фибробластов 1 (FGF-1), гистохимически - повышение содержания гликозаминогликанов и новообразованной тонковолокнистой соединительной ткани [12].

Свойства ГК определяются ее молекулярной массой. Чем выше молекулярная масса ГК, тем более вязким будет раствор даже при ее низких концентрациях. В гинекологии инъецируемые ПГК обладают высокой молекулярной массой. Высокомолекулярная ГК ( 2 МДа) не только имеет объемообразующие свойства, но и участвует в механизмах антиоксидантной защиты, обладает противовоспалительной активностью и подавляет ангиогенез [13].
В гинекологической практике накапливается опыт применения ПГК, который показывает обнадеживающие результаты. В литературе мы нашли публикации, посвященные использованию ГК для лечения вульвовагинальной атрофии, недержания мочи и липодистрофии больших половых губ (БПГ).

Согласно систематическому обзору С.C.M. Dos Santos и соавт. (2021) с участием 335 женщин, не выявлена значимая разница между применением ГК и локальными эстрогенами в отношении атрофии эпителия влагалища, уровня $\mathrm{pH}$, степени пролиферации эпителия и диспареунии [14].

Результаты исследования A. Wierzbicka и соавт. (2021) показали уменьшение диспареунии, сухости влагалища и фиброза у пациенток, перенесших брахитерапию или лучевую терапию по поводу злокачественных новообразований шейки и тела матки, после использования вагинальных суппозиториев с ГК в комбинации с витаминами $\mathrm{A}$ и Е. Похожие данные получены в исследовании S. Dinicola и соавт. (2015) $[15,16]$.

До сих пор существует потребность в разработке и совершенствовании уже имеющихся способов лечения стрессового недержания мочи легкой степени. После периуретрального введения декстраномера и ГК в 84\% случаев наблюдается клиническое выздоровление: отсутствие симптомов недержания мочи, отрицательные кашлевая проба и прием Вальсальвы, которые у 57\% пациенток сохраняются на протяжении 12 месяцев [17]. Однако спустя десятилетие выявлена высокая частота осложнений в месте инъекций (до 16\%), позже данный препарат был снят с производства [18]. В настоящее время для коррекции недержания мочи и дистопии уретры применяется высокоочищенный стабилизированный гиалуронат натрия, эффективность которого предстоит доказать.

Аугментация БПГ является одним из основных направлений эстетической гинекологии. Однако стандарты в области аугментации БПГ в настоящее время только разрабатываются. В ходе систематического обзора S. Jabbour и соавт. (2017), включающего всего две статьи, описывающие введение филлеров на основе ГК в количестве от 2 до 6 мл, выяснилось, что увеличение БПГ - безопасный и эффективный метод, который позволяет достичь высокого уровня удовлетворенности и не вызывает серьезных осложнений [19]. Однако необходимы дальнейшие рандомизированные контролируемые исследования.

Интимная контурная пластика - наиболее распространенная манипуляция в эстетической гинекологии, поэтому представляется важным подробно описать клинический опыт эстетической коррекции наружных половых органов. В процессе интимной контурной пластики имеет значение выбор иглы или канюли для введения наполнителя. Следует помнить, что для объемной коррекции предпочтительно использовать именно канюли, это снизит риск травматизации сосудов и образования гематом, в то же время уменьшается контроль над объемами вводимого препарата. Иглы применяются как для более тонких (поверхностных) инъекций, так и для введения препарата в глубокие (субдермальные) слои кожи [20].

\section{ПОКАЗАНИЯ К ИНТИМНОЙ КОНТУРНОЙ ПЛАСТИКЕ}

Необходимо четко сформулировать показания для проведения интимной контурной пластики и обсудить с пациенткой конечный результат. Выбор препарата, количество и техника его введения определяются, исходя из целей, задач, 
гинекологического статуса женщины и возрастных особенностей. Предварительная беседа с пациенткой - чрезвычайно важный этап, так как именно он позволяет врачу выработать единую общую стратегию и сформировать у пациентки адекватные ожидания.

Функциональные показания:

- врожденные дефекты и приобретенные деформации промежности (послеродовые, послеоперационные и посттравматические), приводящие к нарушению функции мочеполовой системы (рис. 1);

- синдром релаксации влагалища (в комплексной терапии);

- атрофические изменения кожи и слизистых генитальной области;

- трещина задней спайки;

- диспареуния;

- сексуальные дисфункции - снижение либидо, аноргазмия (только в комплексной терапии).

Эстетические показания:

- врожденные дефекты и приобретенные деформации промежности, не приводящие к нарушению мочеполовой функции, но снижающие качество жизни;

- дефицит объема БПГ (возрастная инволюция, последствие резкой потери массы тела и другие причины);

- гипертрофия или деформация малых половых губ, не требующая хирургической коррекции, но снижающая качество жизни (рис. 2).

Рис. 1. Пачиентка А., 34 года. Склерозирующий михен вульвы. Послеродовая деформация промежности. А 一 до введения 1 мл натрия гиалуроната ретикулированного (филлер 25 мг/м^) в преАлверие влагалища; В - после минейно-ретрограАного введения 1 мл фимлера; C - наружные половые органы (НПО) через 8 месяцев после ввеления фимлера; D - сразу после повторного введения 1 м того же фицлера в преАлверие влагалища и нижнюю треть НПО. Здесь и далее иллтострачии авторов

Fig. 1. Patient L., 34 years old. Vulvar lichen sclerosus. Postpartum perineum deformation. A: before injection of $1 \mathrm{~mL}$ of reticulated sodium hyaluronate $(25 \mathrm{mg} / \mathrm{mL}$ filler) into vulvar vestibule; $\mathrm{B}$ : after the linear retrograde injection of $1 \mathrm{~mL}$ of filler; $\mathrm{C}$ : vulva in 8 months after filler injection; D: immediately after repeated injection of $1 \mathrm{~mL}$ of the same filler into vulvar vestibule and the lower third of the vulva. All photos in the paper courtesy of the authors
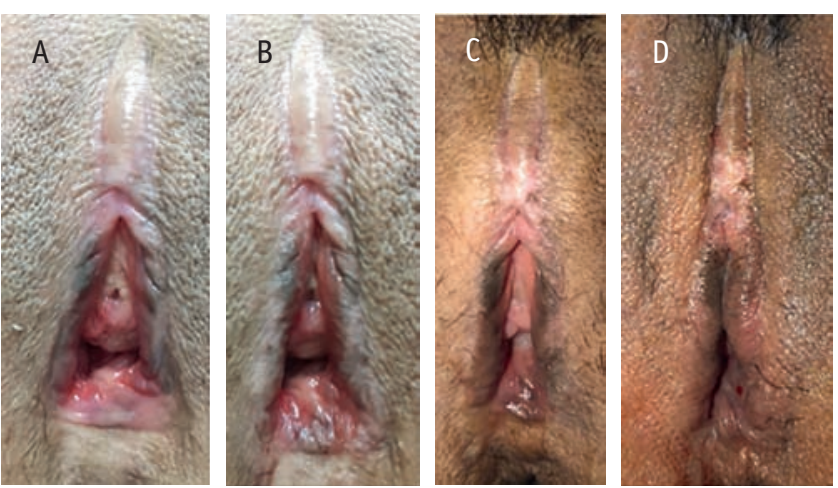

Рис. 2. Введение натрия гиацуроната

ретикулированного 20 мг м в в объеме 2 мл

с целью коррекции гипертрофии малых половых

губ. А - Ао введения фимлера; В - после

аугментации больших половых губ

Fig. 2. Injection of $2 \mathrm{~mL}$ of reticulated sodium hyaluronate (20 $\mathrm{mg} / \mathrm{mL}$ ) for labia minora hypertrophy correction.

A: prior to filler injection; B: after labia majora augmentation
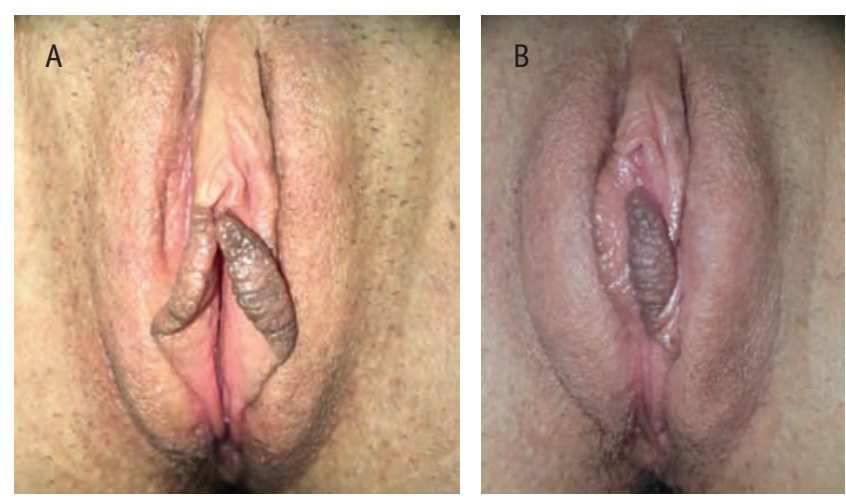

\section{ПРОТИВОПОКАЗАНИЯ К ВВЕДЕНИЮ ПРЕПАРАТОВ} НА ОСНОВЕ ГИАЛУРОНОВОЙ КИСЛОТЫ [13]

Абсолютные противопоказания к введению ПГК:

- индивидуальная непереносимость компонентов препарата;

- беременность и период лактации;

- острые инфекционно-воспалительные заболевания мочеполовой и экстрагенитальных систем и обострения хронических;

- аутоиммунные заболевания, в т. ч. СД в декомпенсированной стадии;

- наличие неизвестного филлера или препарата иных физико-химических свойств в планируемой зоне коррекции;

- период менструации;

- хронические дерматозы в стадии обострения;

- психические расстройства.

Относительные противопоказания к введению ПГК:

- склонность к формированию гипертрофических рубцов;

- наличие филлера такой же природы, но от другого производителя;

- онкологические заболевания;

- клинически значимые нарушения свертываемости крови и прием антикоагулянтов.

\section{ВОЗМОЖНЫЕ ПОБОЧНЫЕ ЭФФЕКТЫ И ОСЛОЖНЕНИЯ}

Введение ПГК производится преимущественно амбулаторно, реже аугментация является частью хирургической операции, например, осуществляется совместно с малоинвазивной леваторопластикой вагинальными нитями. В США в 2007 году дерматологами выполнены почти 11,7 млн косметологических процедур, в том числе хирургического профиля, при этом больше половины - в офисных помещениях. По мере того как число женщин, подвергающихся эстетическим манипуляциям, продолжает расти, все больше появляется публикаций дерматологов, посвященных осложнениям после введения объемообразующих наполнителей, связанным с качеством препарата, работой неквалифицированных врачей или случаями, когда пациентке не известно о раннее 
введенном препарате. Большинство авторов признали, что опыт, соответствие показаниям и грамотная техника введения ПГК являются важными факторами для проведения успешной манипуляции [21].

Нежелательные явления, связанные с введением филлера в область гениталий, могут быть как немедленными (до 24 часов после манипуляции), ранними (от 24 часов до 4 недель), так и отсроченными (более 4 недель), они обусловлены качественными характеристиками препарата, техникой его введения и особенностями пациентки (несоблюдением рекомендаций врача, индивидуальной чувствительностью к введенному препарату) [22]. Ранние побочные реакции, такие как эритема, локальная болезненность и зуд, не требуют лечения и проходят самостоятельно в течение 1-2 дней.

Наиболее частым ранним осложнением интимной контурной пластики у начинающих специалистов является гиперкоррекция - неравномерное и избыточное введение ПГК с образованием комков, узлов и бугристости (рис. 3). Гиперкоррекция - обратимое осложнение, которое можно скорректировать путем локального введения ферментных препаратов (например, гиалуронидазы). Чаще гиперкоррекция сопровождается болевыми ощущениями из-за перерастяжения кожи и сдавления тканей.

К ранним осложнениям также относятся отек и гематомы различной степени выраженности в зависимости от калибра поврежденного сосуда (рис. 4). Данное осложнение корректируется с помощью физиотерапевтического лечения с применением противовоспалительных и рассасывающих мазей (гепариновой) или тепловых манипуляций, таких как радиоволновое терапевтическое воздействие (RF-терапия). В литературе мы не нашли описания случаев некроза после интимной контурной пластики, однако в практике дерматологов-косметологов ишемические поражения встречаются все чаще [23]. Возможные аллергические реакции требуют использования десенсибилизирующих препаратов или введения кортикостероидов.

К поздним осложнениям в основном относятся поздние аллергические реакции, миграция наполнителя, инфицирование, образование гранулем и осумковывание гиалуронового геля. Последнее больше характерно для длительно рассасывающихся наполнителей, таких как гидроксиапатит кальция, полимолочная кислота. Так, в косметологии частота осумковывания ПГК составляет менее $10 \%$. В литературе имеется всего одна публикация, посвященная нетромботической легочной эмболии после аугментации точки G ПГК в объеме около 5 мл, выполненной врачом без соответствующего сертификата [24].

Для учета побочных реакций на введение ПГК в 2020 году Ассоциацией специалистов по эстетической гинекологии был создан реестр осложнений, где можно получить консультацию по ведению пациенток с побочными реакциями.

\section{ЗАКЛЮЧЕНИЕ}

Препараты на основе гиалуроновой кислоты (ПГК) наиболее часто используемые средства для коррекции различных эстетических нарушений, а в последнее время они широко применяются для лечения урогинекологических заболеваний, сопровождающихся сухостью, диспареунией и недержанием мочи. Соблюдение показаний и противопоказаний, правил асептики и антисептики, а также опыт врача
Рис. 3. Гиперкоррекция больших половых губ 2 мл гиалуронового геля 20 мг/м у у пациентки 36 лет (10 Аней после аугментации)

Fig. 3. Labia majora overcorrection with $2 \mathrm{~mL}$ of hyaluronic gel $(20 \mathrm{mg} / \mathrm{mL})$ in 36 y.o. patient (10 days after augmentation)

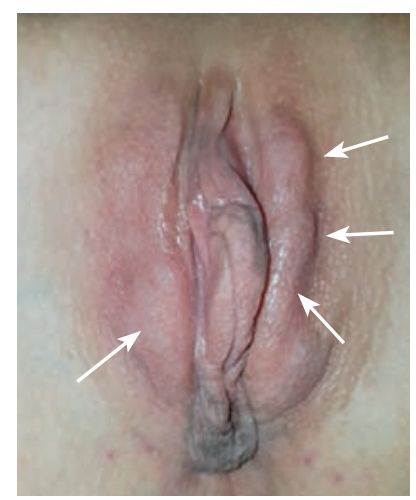

Рис. 4. Введение 2 мл препарата на основе гиалуроновой кислоты 20 мг/мл пациентке 53 мет с целью коррекции возрастной Аиподистрофии

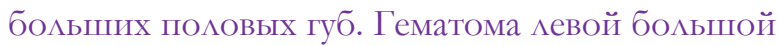
половой губы. А — ло ввеления филлера; В сразу после травмирования сосуда и мгновенного образования гематомы (асимметрия половых губ, флуктуация в среАней трети мевой большой половой губы); C - гематома в стадии рассасывания (5 Аней после аугментации); D после курса физиотерапевтического мечения Fig. 4. Injection of $2 \mathrm{~mL}$ of hyaluronic acid product $(20 \mathrm{mg} / \mathrm{mL})$ to a 53 y.o. patient for age-related labia majora lipodystrophy correction. Left labia majora bruising. A: prior to filler injection; B: immediately after vessel damage and instant bruising (vulvar lip asymmetry, fluctuation in the middle third of left labia majora); C: bruising resolution (5 days after augmentation); D: after a course of physiotherapy

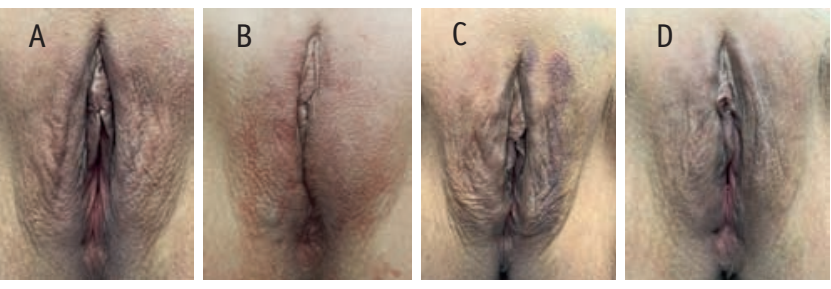

и грамотная техника введения объемообразующих средств являются важными факторами для проведения успешной манипуляции. В то же время пациентка должна следовать рекомендациям врача и быть осведомлена об инъецируемом препарате.

В настоящее время в арсенале гинекологов имеются высокоочищенные гипоаллергенные ПГК, однако доказательная база остается недостаточной, и необходимо проведение хорошо спланированных рандомизированных клинических исследований на большей выборке. 


\section{ЛИTEPATYPA / REFERENCES}

1. Rohrich R.J., Bartlett E.L., Dayan E. Practical approach and safety of hyaluronic acid fillers. Plast. Reconstr. Surg. Glob. Open. 2019; 7(6): e2172. DOI: 10.1097/GOX.0000000000002172

2. Salwowska N.M., Bebenek K.A., Żąło D.A. et al. Physiochemical properties and application of hyaluronic acid: a systematic review. J. Cosmet. Dermatol. 2016; 15(4): 520-6. D0I: 10.1111/jocd.12237

3. Ziganshina M.M., Pavlovich S.V., Bovin N.V. et al. Hyaluronic acid in vascular and immune homeostasis during normal pregnancy and preeclampsia. Acta Naturae. 2016; 8(3): 59-71.

4. Taieb M., Gay C., Sebban S. et al. Hyaluronic acid plus mannitol treatment for improved skin hydration and elasticity. J. Cosmet. Dermatol. 2012; 11(2): 87-92. DOI: 10.1111/j.14732165.2012.00608.x

5. Lacarrubba F., Tedeschi A., Nardone B. et al. Mesotherapy for skin rejuvenation: assessment of the subepidermal low-echogenic band by ultrasound evaluation with cross-sectional B-mode scanning. Dermatol. Ther. 2008; 21(suppl.3): Sl-5. DOI: 10.1111/j.15298019.2008.00234.x

6. Longinotti, C. The use of hyaluronic acid based dressings to treat burns: a review. Burns Trauma. 2014; 2(4): 162-8. DOI: 10.4103/2321-3868.142398

7. Price R.D., Berry M.G., Navsaria H.A. Hyaluronic acid: the scientific and clinical evidence. J. Plast. Reconstr. Aesthet. Surg. 2007; 60(10): 1110-9. D0I: 10.1016/j.bjps.2007.03.005

8. Casale M., Moffa A., Vella P. et al. Hyaluronic acid: perspectives in dentistry. A systematic review. Int. J. Immunopathol. Pharmacol. 2016; 29(4): 572-82. DOI: 10.1177/0394632016652906

9. Price R.D., Myers S., Leigh I.M. et al. The role of hyaluronic acid in wound healing: assessment of clinical evidence. Am. J. Clin. Dermatol. 2005; 6(6): 393-402. DOI: 10.2165/00128071200506060-00006

10. Neuman M.G., Nanau R.M., Oruña-Sanchez L. et al. Hyaluronic acid and wound healing. J. Pharm. Pharm. Sci. 2015; 18(1): 53-60. DOI: $10.18433 / j 3 \mathrm{k} 89 \mathrm{~d}$

11. Dalmedico M.M., Meier M.J., Felix J.V. et al. Hyaluronic acid covers in burn treatment: a systematic review. Rev. Esc. Enferm. USP. 2016; 50(3): 522-8. DOI: 10.1590/S0080-623420160000400020

12. Галеева А.Г. Влияние внутридермального введения экспериментальным животным гиалуронана на содержание коллагена в коже. Наука молодых (Eruditio Juvenium). 2016; 1: 23-7. [Galeeva A.G. The effect of intradermal injection of experimental animals of hyaluronan to the collagen content in the skin. Science of the Young (Eruditio Juvenium). 2016; 1: 23-7. (in Russian)]

13. Губанова Е.И., Шарова А.А., Эрнандес Е.И. и др.; Эрнандес Е.И., ред. Новая косметология. Инъекционные методы в косметологии. М.; 2020: 126-7, 328. [Gubanova E.I., Sharova A.A.,

Поступила / Received: 27.08.2021

Принята к публикации / Accepted: 06.09.2021
Hernandes E.I. et al.; Hernandes E.I., ed. New cosmetology. Injections in cosmetology. M.; 2020. 126-7, 328. (in Russian)]

14. Dos Santos C.C.M., Uggioni M.L.R., Colonetti T. et al. Hyaluronic acid in postmenopause vaginal atrophy: a systematic review. J. Sex. Med. 2021; 18(1): 156-66. DOI: 10.1016/j.jsxm.2020.10.016

15. Wierzbicka A., Mańkowska-Wierzbicka D., Cieślewicz S. et al. Interventions preventing vaginitis, vaginal atrophy after brachytherapy or radiotherapy due to malignant tumors of the female reproductive organs - a systematic review. Int. J. Environ. Res. Public Health. 2021; 18(8): 3932. DOI: 10.3390/ijerph18083932

16. Dinicola S., Pasta V., Costantino D. et al. Hyaluronic acid and vitamins are effective in reducing vaginal atrophy in women receiving radiotherapy. Minerva Ginecol. 2015; 67(6): 523-31.

17. Аполихина И.А., Саидова А.С., Белоусов Д.М. Опыт применения декстраномера/гиалуроновой кислоты («Уродекса») для лечения стрессового недержания мочи у женщин. Журнал акушерства и женских болезней. 2009; LVIII(5): 16-17. [Apolikhina I.A., Saidova A.S., Belousov D.M. The use of dextranomer/ hyaluronic acid (Urodex) for stress urinary incontinence treatment in women. Journal of Obstetrics and Gynecopathy. 2009; LVIII(5): 16-17. (in Russian)]

18. Kirchin V., Page T., Keegan P.E. et al. Urethral injection therapy for urinary incontinence in women. Cochrane Database Syst. Rev. 2017; 7(7): CD003881. DOI: 10.1002/14651858.CD003881.pub4

19. Jabbour S., Kechichian E., Hersant B. et al. Labia majora augmentation: a systematic review of the literature. Aesthet. Surg. J. 2017; 37(10): 1157-64. DOI: 10.1093/asj/sjx056

20. Лифам В.Дж., Меличер Дж.С. Инъекции ботулотоксина и филлеров в клинической косметологии. М.; 2017. 176 c. [Lifam V.J., Melicher J.S. Botulinus toxin and filler injections in clinical cosmetology. M.; 2017. 176 p. (in Russian)]

21. Sturm L.P., Cooter R.D., Mutimer K.L. et al. A systematic review of dermal fillers for age-related lines and wrinkles. ANZ J. Surg. 2011; 81(1-2): 9-17. DOI: 10.1111/j.1445-2197.2010.05351.x

22. Philipp-Dormston W.G., Goodman G.J., De Boulle K. et al. Global approaches to the prevention and management of delayedonset adverse reactions with hyaluronic acid-based fillers. Plast. Reconstr. Surg. Glob. Open. 2020; 8(4): e2730. D0I: 10.1097/ G0X.0000000000002730

23. Urdiales-Gálvez F., Delgado N.E., Figueiredo V. et al. Treatment of soft tissue filler complications: expert consensus recommendations. Aesth. Plast. Surg. 2018; 42(2): 498-510. DOI: 10.1007/s00266017-1063-0

24. Park H.J., Jung K.H., Kim S.Y. et al. Hyaluronic acid pulmonary embolism: a critical consequence of an illegal cosmetic vaginal procedure. Thorax. 2010; 65(4): 360-1. DOI: 10.1136/ thx.2009.128272 D 